\title{
Pengaruh Bauran Pemasaran 4P terhadap Keputusan Pembelian Pupuk Eceran di Toko Tani Makmur Pagar Alam Sumatera Selatan
}

\author{
Ginta Ryan Saputra'), Roswaty ${ }^{2)}$ \\ 1), 2) Universitas Indo Global Mandiri, Palembang, Indonesia \\ Email: gintaryansaputra@yahoo.co.id ${ }^{l)}$,roswaty@uigm.ac.id ${ }^{2}$
}

\begin{abstract}
Abstrak
Penelitian ini bertujuan untuk mengetahui besarnya pengaruh bauran pemasaran 4P terhadap keputusan pembelian pupuk eceran di toko Tani Makmur kota Pagar Alam Sumatera Selatan. Penelitian ini merupakan penelitian asosiatif kuantitatif, dengan jumlah sampel sebanyak 93 responden. Teknik pengambilan sampel yang digunakan adalah purposive nonprobability sampling. Variabel bebas pada penelitian ini adalah produk, harga, tempat, dan promosi, dengan keputusan pembelian sebagai variabel terikat. Hasil penelitian ini menunjukkan, berdasarkan uji F, variabel produk, harga, tempat, dan promosi berpengaruh signifikan secara simultan terhadap keputusan pembelian. Sedangkan berdasarkan uji t, hanya variabel harga yang disimpulkan berpengaruh positif namun tidak signifikan, sedangkan variabel produk, tempat, dan promosi berpengaruh positif dan signifikan terhadap keputusan pembelian. Hasil interpretasi nilai koefisien korelasi (R Square 0,731) menunjukkan variabel produk, harga, tempat, dan promosi memiliki pengaruh yang kuat terhadap keputusan pembelian. Dan nilai koefisien determinasi (Adjusted R Square) menunjukan bahwa pengaruh produk, harga. Tempat, dan promosi terhadap keputusan pembelian adalah sebesar 53,4\%, sedangkan sisanya 46,6\% dipengaruhi oleh faktor lain. Variabel produk adalah variabel yang berpengaruh paling dominan berdasarkan dari nilai t hitung yang paling tinggi yaitu 7,913.
\end{abstract}

Kata Kunci: bauran pemasaran, $4 P$, keputusan pembelian

\begin{abstract}
This study aims to determine the magnitude of the influence of the 4P marketing mix on the decision to purchase retail fertilizer at the Tani Makmur shop, Pagar Alam city, South Sumatra. This research is a quantitative associative study, with a total sample of 93 respondents. The sampling technique used was purposive nonprobability sampling. The independent variables in this study are product, price, place, and promotion, with purchasing decisions as the dependent variable. The results of this study indicate, based on the F test, product variables, price, place, and promotion have a significant effect simultaneously on purchasing decisions. Meanwhile, based on the $\mathrm{t}$ test, only the price variable is concluded to have a positive but insignificant effect, while the product, place, and promotion variables have a positive and significant effect on purchasing decisions. The results of the interpretation of the value of the correlation coefficient (R Square 0.731) show that product, price, place, and promotion variables have a strong influence on purchasing decisions. And the coefficient of determination (Adjusted R Square) shows that the effect of product, price. Place and promotion on purchasing decisions amounted to $53.4 \%$, while the remaining $46.6 \%$ was influenced by other factors. The product variable is the variable that has the most dominant influence based on the highest $t$ value, namely 7.913.
\end{abstract}

Keywords: marketing mix, 4P, purchasing decisions

\section{Pendahuluan}

Pemupukan adalah penambahan unsur hara dalam tanah yang diperlukan untuk memenuhi kebutuhan nutrisi tanaman. Kegiatan pemupukan menggunakan bahan yang dinamakan pupuk. Ada dua jenis pupuk berdasarkan bahan pembuatannya, yang pertama adalah pupuk organik yang berasal dari pembusukan material makhluk hidup, dan yang kedua adalah pupuk anorganik yaitu pupuk yang berasal dari proses rekayasa kimiawi. Pupuk anorganik juga 
dibedakan menjadi beberapa macam berdasarkan unsur hara kandungannya. Ada pupuk urea, NPK, ZA, SP36, dan beberapa jenis yang lain.

Di dalam negeri, terdapat 5 produsen besar pupuk anorganik yang berupa perusahaan BUMN, dan produsen pupuk swasta yang lainnya. Produsen-produsen pupuk ini saling bersaing mendapatkan pasar untuk memasarkan produknya dengan menawarkan keunggulan produk masing-masing. Salah satunya yaitu produk pupuk retail atau pupuk eceran. Pasar produk pupuk eceran pun saat ini bernilai potensial karena selain ukurannya lebih sesuai dengan kebutuhan perkebunan masyarakat di daerah pinggiran dan pedesaan. Di lingkungan masyarakat perkotaan pun kebutuhan akan pupuk eceran juga sudah berkembang dengan dipopulerkannya hobi dan komunitas Urban Farming atau berkebun rumahan dan juga hidroponik.

Sebagai contoh produsen pupuk di Sumatera Selatan, terdapat PT Pupuk Sriwidjaja Palembang atau yang akrab disapa PT Pusri. Di Sumatera Selatan, yang merupakan wilayah pusat produksinya PT Pusri, produk-produk PT Pusri juga harus bersaing mendapatkan pasar karena produk dari produsen pupuk lain sudah membanjiri pasar kebutuhan pertanian dan perkebunan di Sumatera Selatan. Adalah salah satunya di kota Pagar Alam, kota yang terletak di lereng gunung Dempo ini, merupakan daerah yang subur dan banyak menghasilkan komoditas hasil pertanian dan perkebunan berupa buah dan sayur dari pertanian dan perkebunan masyarakatnya. Meskipun terbilang sebagai kota kecil, produk-produk pupuk berbagai jenis dan berbagai merek dapat ditemukan di toko-toko tani disini.

Setiap konsumen memiliki pola perilaku konsumsi yang berbeda-beda. Oleh karena itu, baik sebagai pengecer ataupun produsen, untuk dapat menjual produk yang dipasarkannya sampai ke pembeli, diperlukan melakukan berbagai pendekatan terhadap konsumen dan perilakunya. Juga dalam hal persaingan produk pupuk eceran ini, agar dapat mengarahkan sumber dayanya untuk mencapai tujuan pemasaran secara efektif dan efisien, penting bagi pemasar untuk mengetahui pengaruh bauran pemasaran terhadap keputusan pembelian konsumen.

Berdasarkan uraian latar belakang diatas, maka dirumuskan masalah penelitian sebagai berikut: (1) Bagaimana pengaruh produk, harga, tempat, dan promosi secara parsial terhadap keputusan pembelian pupuk eceran di toko Tani Makmur Pagar Alam Sumatera Selatan?; (2) Bagaimana pengaruh produk, harga, tempat, dan promosi secara simultan terhadap keputusan pembelian pupuk eceran di toko Tani Makmur Pagar Alam Sumatera Selatan?; dan (3) Variabel manakah yang paling dominan mempengaruhi keputusan pembelian pupuk eceran di toko Tani Makmur Pagar Alam Sumatera Selatan?

\section{Tinjauan Pustaka}

\subsection{Bauran Pemasaran}

Bauran Pemasaran adalah alat-alat pemasaran yang digunakan perusahaan untuk mengejar tujuan pemasarannya (Susanti, Halin, \& Kurniawan, 2018; Wadud, 2018). McCarthy dalam Kotler \& Keller (2018) mengklasifikasikan bauran pemasaran menjadi empat kelompok besar, yang disebut empat P: produk (product), harga (price), tempat (place) dan promosi (promotion).

a. Produk mencakup segala sesuatu yang memberikan nilai (value) untuk memuaskan kebutuhan atau keinginan, seperti barang fisik, jasa, tempat, acara, orang dan sebagainya. 
b. Harga, harga tidak hanya berupa nilai moneter yang dibayarkan atau dikeluarkan konsumen, namun juga pengorbanan non-moneter yang dilakukan konsumen dalam rangka mendapatkan hak kepemilikan atau penggunaan sebuah barang atau jasa.

c. Tempat, variabel tempat meliputi logistik perusahaan dan aktivitas pemasaran berkenaan dengan penyediaan dan pendistribusian produk akhir kepada konsumen akhir.

d. Promosi, menurut Tjiptono (2015), promosi merupakan elemen bauran pemasaran yang berfokus pada upaya menginformasikan, membujuk, dan mengingatkan kembali konsumen akan merek dan produk perusahaan. Selanjutnya, Wahid \& Wadud (2020) menyatakan bahwa, di era serba digital sekarang, strategi pemasaran yang efektif adalah melalui media sosial.

\subsection{Perilaku Konsumen}

Perilaku konsumen adalah proses konsumsi yang dialami konsumen dalam rangka memenuhi kebutuhan dan keinginannya (Tjiptono, 2018). Sedangkan menurut Malau (2017), ada 2 bagian perilaku konsumen yang akan mempengaruhi bagaimana mereka merasakan dan bereaksi terhadap stimuli pemasaran, yaitu karakteristik pembeli dan proses keputusan pembelian.

\subsection{Keputusan Pembelian}

Keputusan pembelian adalah niat atau maksud pembelian yang diwujudkan menjadi tindakan pembelian (Irawan, Marnisah, \& Azrai'e, 2016; Marnisah, Saputra, \& Azra'ie, 2016; Kotler \& Keller, 2018; Arifai \& Trihandayani, 2018; Batu, Suryani, Septia, \& Sekaryahya, 2020). Ditambahkan Sunyoto (2014), ada dua hal yang penting dalam keputusan pembelian konsumen, yaitu struktur keputusan pembelian, dan proses pengambilan keputusan membeli.

\subsection{Struktur Keputusan Pembelian}

Dalam Sunyoto (2014), setiap keputusan membeli mempunyai suatu struktur sebanyak tujuh. Komponen-komponen tersebut adalah:

a. Keputusan tentang jenis produk

b. Keputusan tentang bentuk produk

c. Keputusan tentang merek

d. Keputusan tentang penjualnya

e. Keputusan tentang jumlah produk

f. Keputusan tentang waktu pembelian

\subsection{Proses Pengambilan Keputusan Membeli}

Proses pengambilan keputusan membeli dalam Kotler \& Keller (2018) dikenal juga dengan model lima tahap, meliputi:

a. Pengenalan Masalah, awal proses pembelian sudah dapat dikenali ketika pembeli mengenali masalah atau kebutuhan yang dapat dicetuskan oleh rangsangan internal maupun eksternal. Rangsangan internal contohnya lapar, dan haus. Sedangkan rangsangan eksternal yaitu iklan liburan atau mobil.

b. Pencarian Informasi, konsumen yang terangsang kebutuhannya akan terdorong untuk mencari informasi yang lebih banyak. Dalam Tjiptono (2016), identifikasi masalah atau 
kebutuhan memerlukan solusi yang biasanya berupa pembelian barang atau jasa spesifik. Sebelum memutuskan tipe produk, merek spesifik, dan pemasok yang akan dipilih, konsumen biasanya mengumpulkan berbagai informasi mengenai alternatif-alternatif yang ada.

c. Evaluasi Alternatif, setelah terkumpul berbagai alternatif solusi, konsumen kemudian mengevaluasi dan menyeleksinya untuk menentukan pilihan akhir.

d. Keputusan Membeli, dalam tahap evaluasi, para konsumen membentuk preferensi atas merek-merek yang ada di dalam kumpulan pilihan. Konsumen juga dapat membentuk niat untuk membeli merek yang paling disukai. Dalam Kotler \& Keller (2018), dalam melaksanakan maksud pembelian, konsumen bisa mengambil lima sub-keputusan, yaitu merek, dealer, kuantitas, waktu, dan metode pembayaran.

e. Perilaku Pasca Pembelian, tugas pemasar tidak berakhir begitu saja ketika produk dibeli, karena setelah itu evaluasi pasca pembelian akan berlangsung. Hasil akhirnya adalah tingkat kepuasan atau ketidakpuasan pelanggan, yang pada gilirannya menghasilkan konsumen yang berkomitmen kuat, bersedia membeli ulang, dan loyal, atau bahkan sebaliknya, konsumen yang beralih merek, atau menghentikan pemakaian kategori produk yang bersangkutan, atau bahkan hingga memperingatkan orang-orang sekitarnya tentang produk tersebut.

\section{Metodologi}

\subsection{Populasi}

Berdasarkan pertimbangan tren permintaan pupuk yang mengikuti periode musim tanam dalam satu tahun, dan hasil observasi di toko Tani Makmur, populasi dihitung berdasarkan jumlah pembelian pupuk eceran dalam periode satu tahun di toko Tani Makmur, dan didapati nilai populasi 1.312 pembelian.

\subsection{Sampel}

Untuk menentukan sampel, digunakan rumus Slovin dari nilai populasi, dan didapat jumlah sampel yang disyaratkan sebanyak 93 sampel.

\subsection{Teknik Pengambilan Sampel}

Teknik pengambilan sampel yang digunakan dalam penelitian ini adalah purposive nonprobablity sampling

\subsection{Teknik Pengumpulan Data}

Teknik pengumpulan data yang digunakan dalam penelitian adalah menggunakan metode observasi, wawancara, dan kuisioner.

\subsection{Teknik Analisis}

Teknik analisis yang digunakan dalam penelitian meliputi
a. Analisis Deskriptif
b. Uji Validitas dan Reliabilitas
c. Uji Asumsi Klasik yang meliputi Uji Normalitas, Uji Heteroskedesitas, dan Uji Multikolinieritas


d. Analisis Regresi Linier Berganda

e. Uji Hipotesis meliputi Uji t dan Uji F

f. Analisa Koefisien Korelasi dan Determinasi

\section{Hasil dan Pembahasan}

\subsection{Analisis Deskriptif}

Dalam analisis deskriptif disajikan data karakteristik responden sampel berdasarkan jenis kelamin, umur, pendidikan, dan tujuan penggunaan pupuk.

Tabel 1. Responden Berdasakan Jenis Kelamin

\begin{tabular}{|l|l|l|l|}
\hline No & Jenis Kelamin & Jumlah & Persentase \\
\hline 1 & Laki-Laki & 62 orang & $66,7 \%$ \\
\hline 2 & Perempuan & 31 orang & $33,3 \%$ \\
\hline & Total & 93 orang & $100 \%$ \\
\hline
\end{tabular}

Tabel 2. Responden Berdasarkan Umur

\begin{tabular}{|l|l|l|l|}
\hline No & Umur & Jumlah & Persentase \\
\hline 1 & $26-35$ tahun & 30 & $32,26 \%$ \\
\hline 2 & $36-45$ tahun & 19 & $20,43 \%$ \\
\hline 3 & $46-55$ tahun & 33 & $35,48 \%$ \\
\hline 4 & 56 tahun ke atas & 11 & $11,83 \%$ \\
\hline & Total & 93 & $100 \%$ \\
\hline
\end{tabular}

Tabel 3. Responden Berdasarkan Pendidikan

\begin{tabular}{|l|l|l|l|}
\hline No & Pendidikan Terakhir & Jumlah & Persentase \\
\hline 1 & SD - SMP & 20 & $21,50 \%$ \\
\hline 2 & SMA - D3 & 33 & $35,48 \%$ \\
\hline 3 & S1 & 40 & $43,02 \%$ \\
\hline & Total & 93 & $100 \%$ \\
\hline
\end{tabular}


Tabel 4. Responden Berdasarkan Penggunaan Pupuk

\begin{tabular}{|l|l|l|l|}
\hline No & Tujuan Pemakaian Pupuk & Jumlah & Persentase \\
\hline 1 & Bertani & 20 & $21,50 \%$ \\
\hline 2 & Berkebun dengan lahan & 46 & $49,46 \%$ \\
\hline 3 & Berekebun Rumahan & 20 & $21,50 \%$ \\
\hline 4 & Hobi Tanaman Hias & 7 & $7,54 \%$ \\
\hline & Total & 93 & $100 \%$ \\
\hline
\end{tabular}

\subsection{Uji Validitas dan Uji Reliabilitas}

Uji validitas variabel produk, harga, tempat, dan promosi disajikan di tabel 5,6,7, dan 8 .

Tabel 5. Uji Validitas Variabel Produk

\begin{tabular}{|l|l|l|l|}
\hline Item Pertanyaan & r hitung & r tabel & Keterangan \\
\hline Produk $X_{1 \_}$ & 0,477 & 0,2072 & valid \\
\hline Produk $X_{1 \_}$ & 0,352 & 0,2072 & valid \\
\hline Produk $X_{1 \_}$ & 0,309 & 0,2072 & valid \\
\hline Produk $X_{1 \_} 4$ & 0,563 & 0,2072 & valid \\
\hline Produk $X_{1 \_}$ & 0,514 & 0,2072 & valid \\
\hline
\end{tabular}

Tabel 6. Uji Validitas Variabel Harga

\begin{tabular}{|l|l|l|l|}
\hline Item Pertanyaan & r hitung & r tabel & Keterangan \\
\hline Harga $\mathrm{X}_{2} 1$ & 0,353 & 0,2072 & valid \\
\hline Harga $\mathrm{X}_{2} 2$ & 0,519 & 0,2072 & valid \\
\hline Harga $\mathrm{X}_{2} 3$ & 0,787 & 0,2072 & valid \\
\hline Harga $\mathrm{X}_{2} 4$ & 0,636 & 0,2072 & valid \\
\hline
\end{tabular}

Tabel 7. Uji Validitas Variabel Tempat

\begin{tabular}{|l|l|l|l|}
\hline Item Pertanyaan & r hitung & r tabel & Keterangan \\
\hline Tempat $\mathrm{X}_{3} \_1$ & 0,494 & 0,2072 & valid \\
\hline
\end{tabular}




\begin{tabular}{|l|l|l|l|}
\hline Tempat $X_{3} 2$ & 0,531 & 0,2072 & valid \\
\hline Tempat $X_{3} 3$ & 0,614 & 0,2072 & valid \\
\hline Tempat $X_{3} 4$ & 0,526 & 0,2072 & valid \\
\hline
\end{tabular}

Tabel 8. Uji Validitas Variabel Promosi

\begin{tabular}{|l|l|l|l|}
\hline Item Pertanyaan & r hitung & r tabel & Keterangan \\
\hline Promosi $X_{4} \_$ & 0,488 & 0,2072 & valid \\
\hline Promosi $X_{4} \_$ & 0,337 & 0,2072 & valid \\
\hline Prromosi $X_{4} 3$ & 0,409 & 0,2072 & valid \\
\hline Promosi $X_{4} 44$ & 0,323 & 0,2072 & valid \\
\hline Promosi $X_{4} 5$ & 0,461 & 0,2072 & valid \\
\hline Promosi $X_{6} 5$ & 0,636 & 0,2702 & valid \\
\hline
\end{tabular}

Uji reliabilitas variabel produk, harga, tempat, dan promosi disajikan dalam tabel 9.

Tabel 9. Uji Reliabilitas Variabel Produk, Harga, Tempat, dan Promosi

\begin{tabular}{|l|l|l|l|}
\hline Variabel & Nilai Cronbach Alpha & Nilai Minimal & Keterangan \\
\hline Produk & 0,602 & 0,6 & Reliabel \\
\hline Harga & 0,717 & 0,6 & Reliabel \\
\hline Tempat & 0,668 & 0,6 & Reliabel \\
\hline Promosi & 0,631 & 0,6 & Reliabel \\
\hline
\end{tabular}

\subsection{Uji Asumsi Klasik}

\subsubsection{Uji Normalitas}

Uji normalitas yang digunakan adalah dengan metode uji Kolgomorov Smirnov. Data dikatakan berdistirbusi normal atau memenuhi asumsi uji normalitas jika nilai residual yang dihasilkan di atas nilai signifikansi yang ditetapkan. 
Tabel 10. Nilai Uji Kolgomorov Smirnov

\begin{tabular}{|c|c|c|}
\hline \multicolumn{3}{|c|}{ e Kolmogorov-Smirnov Test } \\
\hline & & $\begin{array}{l}\text { Unstandardiz } \\
\text { ed Residual }\end{array}$ \\
\hline $\mathrm{N}$ & & 144 \\
\hline \multirow[t]{2}{*}{ Normal Parameters $\mathrm{a}, \mathrm{b}$} & Mean & .0000000 \\
\hline & Std. Deviation & 1.01707099 \\
\hline \multirow{3}{*}{$\begin{array}{l}\text { Most Extreme } \\
\text { Differences }\end{array}$} & Absolute & .065 \\
\hline & Positive & .065 \\
\hline & Negative & -.062 \\
\hline Kolmogorov-Smirnov Z & & .778 \\
\hline Asymp. Sig. (2-tailed) & & .580 \\
\hline
\end{tabular}

Data disimpulkan memenuhi asumsi normalitas atau berdistribusi normal karena nilai residu $(0,580)$ lebih besar dari nilai signifikasi $(\alpha)$ yang ditetapkan $(0,1)$.

\subsubsection{Uji Multikolinieritas}

Tabel 11. Uji Multikolinieritas Data

\begin{tabular}{|l|l|l|l|}
\hline Variabel & Nilai Tolerance & Nilai VIF & Keterangan \\
\hline Produk & 0,835 & 1,198 & Bebas dari Multikolinieritas \\
\hline Harga & 0,743 & 1,346 & Bebas dari Multikolinieritas \\
\hline Tempat & 0,727 & 1,375 & Bebas dari Multikolinieritas \\
\hline Promosi & 0,837 & 1,194 & Bebas dari Multikolinieritas \\
\hline
\end{tabular}

Uji multikolinieritas yang digunakan adalah dengan mendeteksi nilai Variance Inflation Factor (VIF), jika nilai VIF tidak lebih yang dari 10 dan nilai tolerance tidak kurang dari 0,1 , maka model dapat dikatakan terbebas dari multikolinieritas.

\subsubsection{Uji Heteroskedesitas}

Uji heteroskedesitas yang dilakukan pada penelitian ini yaitu dengan metode scatter plot.

Gambar 1. Scatter Plot Nilai Regresi dan Nilai Residu

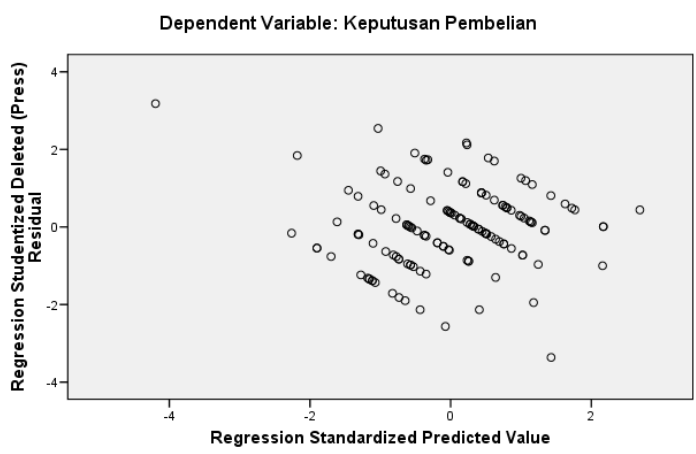

Dari Scatter Plot yang dihasilkan, tampak pola menyebar, sehingga model dikatakan memenuhi syarat Homoskedesitas atau terbebas dari Heteroskedesitas. 


\subsubsection{Analisis Regresi Linier Berganda}

Tabel 12. Koefisien Regresi

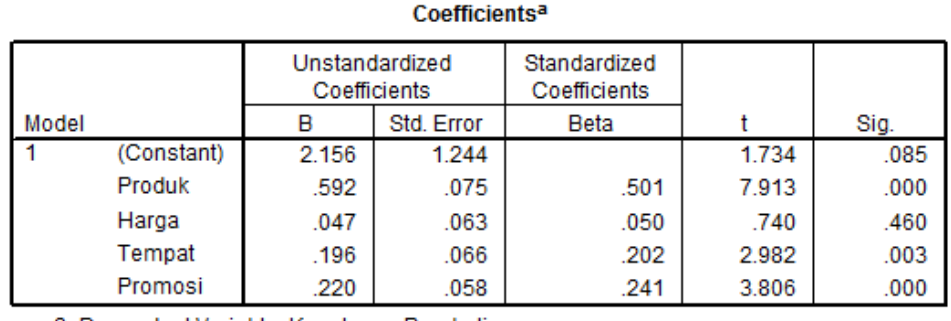

a. Dependent Variable: Keputusan Pembelian

Nilai koefisien diatas, jika dimasukkan ke dalam persamaan regresi berganda $\mathrm{Y}=\mathrm{a}+\mathrm{b}_{1} \mathrm{X}_{1}+$ $\mathrm{b}_{2} \mathrm{X}_{2}+\mathrm{b}_{3} \mathrm{X}_{3}+\mathrm{b}_{4} \mathrm{X}_{4}$ dapat dijelaskan sebagai berikut.

Hasil perhitungan menunjukkan nilai konstanta $a=2,156$, dan koefisien $b_{1}=0,592, b_{2}=0,047$, $b_{3}=0,196$, dan $b_{4}=0,220$. Sehingga persamaan regresi linier menjadi:

$\mathrm{Y}=2,156+0,592 \mathrm{X}_{1}+0,047 \mathrm{X}_{2}+0,196 \mathrm{X}_{3}+0,220 \mathrm{X}_{4}$

dengan keterangan:

$\mathrm{Y}=$ Keputusan Pembelian, $\mathrm{X}_{1}=$ Produk, $\mathrm{X}_{2}=$ Harga, $\mathrm{X}_{3}=$ Tempat, $\mathrm{X}_{4}=$ Promosi

$\mathrm{a}=$ konstanta $=2,156$; artinya ketika Produk, Harga, Tempat, dan Promosi sebesar 0, Keputusan Pembelian memiliki nilai 2.156

$\mathrm{b}_{1}=$ koefisien regresi Produk, sebesar 0,592, artinya ketika Produk mengalami kenaikan satu satuan, akan berdampak pada Keputusan Pembelian mengalami kenaikan sebesar 0,592

$\mathrm{b}_{2}=$ koefisien regresi Harga, sebesar 0,047, artinya ketika Harga mengalami kenaikan satu satuan, akan berdampak pada Keputusan Pembelian mengalami kenaikan sebesar 0,047

$\mathrm{b}_{3}=$ koefisien regresi Tempat, sebesar 0,196, artinya ketika Tempat mengalami kenaikan satu satuan, akan berdampak pada Keputusan Pembelian mengalami kenaikan sebesar 0,196

$\mathrm{b}_{4}=$ koefisien regresi Promosi, sebesar 0,220, artinya ketika Promosi mengalami kenaikan sebesar satu satuan, maka akan berdampak pada keputusan Pembelian mengalami kenaikan sebesar 0,220

\subsection{Uji Hipotesis}

\subsubsection{Uji t}

Uji t dilakukan untuk membuktikan adanya pengaruh masing-masing variabel-variabel bebas terhadap variabel terikat. Adapun langkah uji $t$ yang dilakukan adalah dengan menghitung $\mathrm{t}$ hitung variabel bebas dan membandingkan dengan nilai $t$ tabel. Jika nilai $t$ hitung $>t$ tabel, maka koefisien regresi tidak dapat dianggap 0 atau $\mathrm{H} 0$ ditolak, sehingga terbukti terdapat pengaruh variabel bebas terhadap variabel terikat. Sebelumnya, ditentukan dulu nilat $\mathrm{t}$ tabel.

$\mathrm{t}$ tabel $=\alpha, \mathrm{df}$

dengan $\alpha=10 \%$ atau 0,1 dan $\mathrm{df}($ derajat kebebasan $)=\mathrm{n}-\mathrm{k}=93-5=88$

maka t tabel $=0,1(88)=1,663$

Tabel 13. Nilai t Hitung 
Coefficients $^{a}$

\begin{tabular}{|c|c|c|c|c|c|c|}
\hline \multirow{2}{*}{\multicolumn{2}{|c|}{ Model }} & \multicolumn{2}{|c|}{$\begin{array}{c}\text { Unstandardized } \\
\text { Coefficients }\end{array}$} & \multirow{2}{*}{$\begin{array}{c}\text { Standardized } \\
\text { Coefficients } \\
\text { Beta }\end{array}$} & \multirow[b]{2}{*}{$t$} & \multirow[b]{2}{*}{ Sig. } \\
\hline & & $\mathrm{B}$ & Std. Error & & & \\
\hline \multirow[t]{5}{*}{1} & (Constant) & 2.156 & 1.244 & & 1.734 & .085 \\
\hline & Produk & .592 & .075 & .501 & 7.913 & .000 \\
\hline & Harga & .047 & .063 & .050 & .740 & .460 \\
\hline & Tempat & .196 & .066 & .202 & 2.982 & .003 \\
\hline & Promosi & .220 & .058 & 241 & 3.806 & .000 \\
\hline
\end{tabular}

a. Dependent Variable: Keputusan Pembelian

Uji t juga dapat dilakukan dengan membandingkan nilai signifikansi dari tabel koefisien, jika nilai sig $<0,05$ maka $\mathrm{H} 0$ ditolak dan $\mathrm{H} 1$ diterima.

Berdasarkan nilai t hitung pada tabel koefisien pada tabel 4.23 terlihat bahwa:

a. Pada variabel Produk, nilai t hitung $=7.913,>\mathrm{t}$ tabel $(1,663)$, dan nilai sig $=0,00<0,05$, sehingga H0 ditolak, dan disimpulkan terdapat pengaruh Produk terhadap Keputusan Pembelian Pupuk Eceran.

b. Pada variabel Harga, nilai t hitung $=0,740,<\mathrm{t}$ tabel $(1,663)$, dan nilai sig $=0,460,>0,05$, sehingga H0 diterima, dan disimpulkan tidak ada pengaruh harga terhadap Keputusan Pembelian Pupukk Eceran.

c. Pada variabel Tempat, nilai $t$ hitung $=2,982,>t$ tabel $(1,663)$, dan nilai sig $=0,03,<0,05$, sehingga H0 ditolak, dan disimpulkan terdapat pengaruh Tempat terhadap Keputusan Pembelian Pupuk Eceran

d. Pada variabel Promosi, nilai t hitung $3,806,>\mathrm{t}$ tabel $(1,663)$, dan nilai sig $=0,00,<0,05$, sehingga H0 ditolak, dan disimpulkan terdapat pengaruh Promosi terhadap Keputusan Pembelian Pupuk Eceran.

\subsubsection{Uji F}

Uji $\mathrm{F}$ dilakukan dengan membandingkan nilai $\mathrm{F}$ hitung dengan nilai $\mathrm{F}$ tabel, jika nilai $\mathrm{F}$ hitung $>\mathrm{F}$ tabel, maka $\mathrm{H} 0$ ditolak, koefisien regresi tidak bisa dianggap 0 , dan dengan kata lain terdapat pengaruh variabel-variabel bebas terhadap variabel terikat secara bersamaan. Uji $F$ juga bisa dilakukan dengan membandingkan nilai sig dari tabel Anova di SPSS, jika nilai sig < 0,05 maka H0 ditolak, H1 diterima, dan disimpulkan terdapat pengaruh variabel bebas terhadap variabel terikat secara simultan.

Tabel 14. Nilai F Tabel Anova

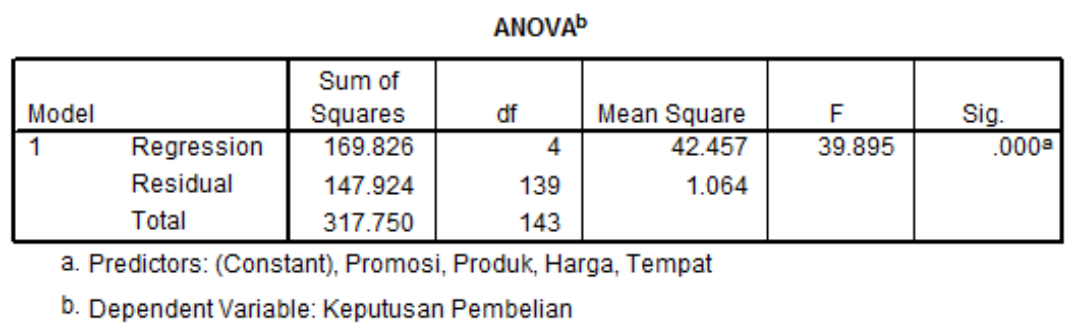

Kemudian menentukan nilai $\mathrm{F}$ tabel:

Nilai $F($ Anova $)=39,985$

$\mathrm{F}$ dimana $\mathrm{v}_{1}=4$ dan $\mathrm{v}_{2}=93-4-1=88$ 
Nilai F tabel $(0,10 ; 5,88)=1,91$

Maka, F hitung $(39,985)>\mathrm{F}$ tabel $(1,91)$, dan nilai sig $=0,00<0,05$, maka H0 ditolak, dengan begitu, dapat disimpulkan, terdapat pengaruh variabel Produk, Harga, Tempat, dan Promosi terhadap Keputusan Pembelian Pupuk Eceran secara simultan.

\subsubsection{Analisa Koefisien Korelasi dan Determinasi}

Tabel 15. Nilai Koefisien Korelasi dan Determinasi di Tabel Model Summary

Model Summary
\begin{tabular}{|l|c|c|c|c|}
\hline Model & R & R Square & $\begin{array}{c}\text { Adjusted } \\
\text { R Square }\end{array}$ & $\begin{array}{c}\text { Std. Error of } \\
\text { the Estimate }\end{array}$ \\
\hline 1 & $.731^{\mathrm{a}}$ & .534 & .521 & 1.032 \\
\hline
\end{tabular}
a. Predictors: (Constant), Promosi, Produk, Harga,
Tempat
b. Dependent Variable: Keputusan Pembelian

\subsubsection{Koefisien Korelasi}

Dilambangkan dengan huruf $r$ dengan rentang nilai dari -1 sampai +1 . Nilai $r$ yang mendekati -1 atau +1 menunjukkan adanya hubungan yang kuat antara variabel bebas dan terikat, sementara nilai $r$ yang mendekati 0 menunjukkan lemahnya hubungan di antara variabel bebas dan variabel terikat tersebut. Sementara nilai negatif (-) atau positif $(+)$ menunjukkan arah hubungan tersebut.

Dalam melakukan interpretasi kekuatan hubungan antara variabel bebas dan terikta tersebut, digunakan tabel interpretasi nilai r sebagai berikut dalam Sugiyono (2013).

Tabel 16. Tabel Interpretasi Koefisien Korelasi

\begin{tabular}{|l|l|}
\hline Nilai $r$ & Tingkat Hubungan \\
\hline $0,00-0,199$ & Sangat Lemah \\
\hline $2,00-3,99$ & Lemah \\
\hline $4,00-5,99$ & Sedang \\
\hline $6,00-7,99$ & Kuat \\
\hline $8,00-9,99$ & Sangat Kuat \\
\hline
\end{tabular}

Dari nilai $r$ hasil pengolahan data SPSS seperti ditampilkan di tabel 15 , maka didapat nilai $r$ 0,731. Berdasarkan tabel interpretasi korelasi di tabel 16 seperti dalam Sugiyono (2013), maka disimpulkan bahwa antara variabel Produk, Harga, Tempat, dan Promosi memiliki pengaruh yang kuat terhadap Keputusan Pembelian Pupuk Eceran.

\subsubsection{Koefisien Determinasi}

Berdasarkan hasil pengolahan di tabel 15 juga, nilai koefisien determinasi (R adjusted Square) pada penelitian ini adalah 0,534.

Dalam Kurniawan (2014), jika KD $=\mathrm{r}^{2} \times 100 \%=0,534 \mathrm{X} 100 \%=53,4 \%$. Maka dapat disimpulkan, pengaruh produk, harga, tempat, dan promosi terhadap keputusan pembelian 
pupuk ecerean adalah sebesar 53,4\%. Sedangkan sisanya 100\% - 53,4\% $=46,6 \%$, dipengaruhi oleh faktor lain selain bauran pemasaran produk, harga, tempat, dan promosi.

\section{Kesimpulan}

a. Berdasarkan hasil penelitian, nilai t tabel adalah 1,663 sedangkan nilai t hitung variabel produk, harga, tempat, dan promosi secara beurutan adalah 7,913, 0,740, 2,982, dan 3,806. Maka dapat disimpulkan terdapat pengaruh variabel produk, harga, tempat, dan promosi secara parsial terhadap keputusan pembelian. Namun, hanya variabel produk, tempat, dan promosi yang berpengaruh signifikan.

b. Berdasarkan nilai $F$ tabel 1,91 , dan nilai $F$ hitung pada tabel Anova yaitu 39,985. Nilai $F$ hitung lebih besar daripada F tabel. Sehingga, dapat disimpulkan terdapat pengaruh variabel produk, harga, tempat, dan promosi secara simultan terhadap keputusan pembelian.

c. Berdasarkan nilai t hitung dari tabel Coefficients, variabel produk memiliki nilai t paling tinggi sehingga dapat disimpulkan bahwa variabel produk berpengaruh paling dominan terhadap keputusan pembelian.

d. Berdasarkan nilai korelasi dari tabel koefisien korelasi Model Summary, nilai $\mathrm{R}$ yang dihasilkan adalah 0,731. Mengacu pada tabel interpretasi nilai korelasi dalam Kurniawan (2014), dapat disimpulkan bahwa pengaruh variabel produk, harga, tempat, dan promosi terhadap keputusan pembelian dikategorikan dalam tingkat hubungan yang kuat.

e. Berdasarkan nilai koefisien determinasi dari tabel koefisien korelasi Model Summary, menunjukkan nilai R Adjusted Square 0,534 yang berarti pengaruh variabel produk, harga, tempat, dan promosi terhadap keputusan pembelian pupuk eceran adalah sebesar $53,4 \%$, sedangkan sisanya $46,4 \%$ dipengaruhi oleh variabel lain.

\section{Saran}

Berdasarkan hasil analisis yang telah dilakukan maka penulis memberikan saran dari hasil penelitian:

a. Bagi Perusahaan

Hasil dari penelitian bahwa terdapat pengaruh simultan antara produk, harga, tempat, dan promosi terhadap keputusan pembelian pupuk eceran di toko Tani Makmur kota Pagar Alam Sumatera Selatan. Maka, toko Tani Makmur, maupun juga produsen agar terus memperhatikan keunggulan bersaing berupa empat variabel yaitu produk, harga, tempat, dan promosi karena terbukti mempengaruhi keputusan pembelian konsumen pupuk eceran. Pengaruh parsial hanya terdapat pada variabel produk, tempat, dan promosi. Maka agar produsen pupuk eceran, berinovasi lagi menciptakan keunggulan bersaing dalam tiga variabel tersebut.

b. Bagi Penelitian Selanjutnya

Berdasarkan hasil penelitian, analisa koefisien determinasi menunjukkan bahwa 46,6\% faktor yang mempengaruhi keputusan pembelian konsumen pupuk eceran berasal dari variabel lain. Maka, hendaknya pada penelitian selanjutnya agar dapat menganalisa dan menyempunakan lagi penelitian serupa dengan variabel-variabel lain yang ikut mempengaruhi keputusan pembelian produk eceran. 


\section{Referensi}

Adi Nugroho, Yundhiya, Arianti, Maya. 2018. Pengaruh Promosi Air Asia Indonesia melalui Instagram terhadap Keputusan Pembelian (survey terhadap followers akun @airasia_indo).Eproceeding of Management vol. 5 no. 2 Agustus 2018. Hal 1932-1939.

Ahmad, Farhan, Martini, Erni. 2018. Pengaruh Promotion Mix terhadap Keputusan Pembelian produk Bright Gas (studi pada masyarakat pengguna Bright Gas di kabupaten Garut. Eproceeding of Management vol. 5 no. 2 Agustus 2018. Hal 1940-1947.

Ananingsih, Tuti. Hasiholan, Leonardo, Budi, Wahyono, Eko Hadi. 2018. Pengaruh Kualitas Produk, Promosi, Harga, dan Saluran Distribusi terhadap Keputusan Pembelian Produk Jhonson \& Jhonson Indonesia. Jurnal. Universitas Pandanaran Semarang.

Arifai, A. A., \& Trihandayani, Z. (2018). HARGA, KUALITAS PRODUK DAN MEREK TERHADAP KEPUTUSAN PEMBELIAN TAS KW CARTIER DI KALANGAN MAHASISWI SEBAGAI PENUNJANG PENAMPILAN KULIAH. Jurnal Ilmiah Ekonomi Global Masa Kini, 8(3), 16-22.

Batu, R. L., Suryani, N. I., Septia, N., \& Sekaryahya, P. F. (2020). Pengaruh Harga dan Inovasi Layanan Aplikasi terhadap Keputusan Penggunaan Jasa Taksi Express: Survei pada Pengunduh Aplikasi Express Taxis. Jurnal Nasional Manajemen Pemasaran \& SDM, 1(01), 1-22. https://doi.org/10.47747/jnmpsdm.v1i01.6

Irawan, D., Marnisah, L., \& Azrai'e, K. R. (2018). ANALISIS PRODUK DAN HARGA TERHADAP KEPUTUSAN MAHASISWA UNIVERSITAS IGM MEMBELI SMARTPHONE SAMSUNG. Jurnal Ilmiah Ekonomi Global Masa Kini, 8(2), 35-41.

Kotler, Philip \& Keller, Kevin L. 2018. Manajemen Pemasaran Edisi 13 (13 ed.). (B. Molan, Trans.) PT Erlangga.

Kurniawan, Albert. 2014. Metode Riset Untuk Ekonomi \& Bisnis. Bandung: Penerbit Alfabeta.

Malau, Harman. 2017. Manajemen Pemasaran. Bandung: Penerbit Alfabeta.

Marnisah, L., Saputra, D., \& Azra'ie, K. R. (2016). ANALISA EFEKTIFITAS PROMOSI TERHADAP KEPUTUSAN KONSUMEN PADA MEMBELI SEMEN BARURAJA DI KELURAHAN SEKIP JAYA KECAMATAN KEMUNING PALEMBANG. Jurnal ilmiah Ekonomi Global masa kini, 7(3), 16-20.

Sugiyono. 2013. Statistika Untuk Penelitian. Bandung: Penerbit Alfabeta.

Sujarweni, V Wiratna. 2015. Metode Penelitian Bisnis \& Ekonomi. Yogyakarta: Pustaka Baru Press.

Sunyoto, Danang. 2014. Konsep Dasar Riset Pemasaran \& Perilaku Konsumen. Yogyakarta: Center for Publishing Academy Service.

Susanti, N., Halin, H., \& Kurniawan, M. (2018). PENGARUH BAURAN PEMASARAN (4P) TERHADAP KEPUTUSANPEMBELIAN PERUMAHAN PT. BERLIAN BERSAUDARA PROPERTINDO (Studi Kasus Perumahan Taman Arizona 1 Taman Arizona 2 dan Taman Arizona 3 di Talang Jambi Palembang). Jurnal Ilmiah Ekonomi Global Masa Kini, 8(1), 43-49.

Tjiptono, Fandy. \& Diana, Anastasia. 2016. Pemasaran. Yogyakarta: CV Andi Offset.

Tjiptono, Fandy. 2015. Strategi Pemasaran Edisi 4. Yogyakarta: CV Andi Offset. 
Wadud, M. (2018). BAURAN PEMASARAN JASA (3 Ps: PEOPLE, PROCESS \& PHYSICAL EVIDENCE) BAGI KEPUASAN PELANGGAN. Jurnal Ilmiah Ekonomi Global Masa Kini, 8(1), 21-29.

Wahid, R. M., \& Wadud, M. SOCIAL MEDIA MARKETING ON INSTAGRAM: WHEN IS THE MOST EFFECTIVE POSTING TIMING?. 